\title{
Anti diabetic property of aqueous extract of Stevia rebaudiana Bertoni leaves in Streptozotocin-induced diabetes in albino rats
}

\author{
Uswa Ahmad ${ }^{1}$ and Rabia Shabir Ahmad ${ }^{1,2^{*}}$
}

\begin{abstract}
Background: Stevia (Stevia rebaudiana) natural, non-caloric sugar substitute is rich source of pharmacologically important glycoside stevioside that is linked to the pathology and complications of diabetes.

Methods: The current research was carried out to explore the anti-diabetic effect of aqueous extract of Stevia rebaudiana leaves in albino rats. For this purpose, diabetes was induced by administration of streptozotocin (40 mg/kg body weight, intraperitoneally). The diabetic rats were administered with aqueous stevia extract at different dose levels (200, 300, 400 and 500 ppm/kg b.w) for 8 weeks; the control rats were fed basal diet during this period.

Results: Stevia aqueous extract improved caloric management and weight control by decreasing the feed intake and body weight gain. Furthermore, intake of stevia extract resulted in significant $(P<0.05)$ decrease in the random blood glucose level $(-73.24 \%)$ and fasting blood glucose $(-66.09 \%)$ and glycosylated (HbA1c) hemoglobin (5.32\%) while insulin $(17.82 \mu \mathrm{lU} / \mathrm{mL})$ and liver glycogen $(45.02 \mathrm{mg} / \mathrm{g})$ levels significantly improved in the diabetic rats, compared with the diabetic and non-diabetic control rats after 8 weeks study period.
\end{abstract}

Conclusions: It is concluded that aqueous extact of stevia has anti-diabetic effects in albino rats, and therefore could be promising nutraceutical therapy for the management of diabetes and its associated complications.

Keywords: Diabetes, Fasting blood glucose, Insulin, HbA1c, Liver glycogen, Random blood glucose, Stevia rebaudiana bertoni, Stevioside

\section{Background}

Diabetes mellitus is a group of metabolic diseases characterized by chronic hyperglycemia resulting from defects in insulin secretion, insulin action, or both [1]. According to World Health Organization Diabetes mellitus will become the seventh leading cause of death worldwide in 2030 [2]. Through proper diet, exercise and pharmacologic interventions, the incidence of diabetes can be overcome [3]. The pharmacological drugs used for the treatment of diabetes, are either too

\footnotetext{
* Correspondence: rabiaahmad@gcuf.edu.pk

'Department of Food Science, Nutrition \& Home Economics, Government College University, Allama lqbal Road, Faisalabad 38000, Pakistan

${ }^{2}$ Institute of Home and Food Sciences, Government College University, Faisalabad 38000, Pakistan
}

(c) The Author(s). 2018 Open Access This article is distributed under the terms of the Creative Commons Attribution 4.0 International License (http://creativecommons.org/licenses/by/4.0/), which permits unrestricted use, distribution, and reproduction in any medium, provided you give appropriate credit to the original author(s) and the source, provide a link to the Creative Commons license, and indicate if changes were made. The Creative Commons Public Domain Dedication waiver (http://creativecommons.org/publicdomain/zero/1.0/) applies to the data made available in this article, unless otherwise stated.

expensive or have certain adverse side effects. Therefore, for the treatment of diabetes mellitus many traditional plants have been preferred as natural source of drugs [4] because they are considered to be safe, less toxic than synthetic ones [5] and have strong antioxidant activities due to which these plants become more effective against diabetes [6]. Stevia rebaudiana Bertoni as a traditional plant is famous due to its sweet taste and beneficial effects in blood glucose regulation. Stevia rebaudiana Bertoni (family Asteraceae) popularly known as stevia, sweet weed, honey leaf and sweet herb of Paraguay [7]. Stevia leaves contained complex mixture of diterpene glycosides including stevioside, steviolbioside, rebaudiosides (A, B, C, D, E) and dulcoside A but the major sweet constituents are stevioside and rebaudioside A $[8,9]$. Natural 
non-caloric sweetener stevioside (a major component of stevia) is $100-300$ times sweeter than sucrose and have been extensively used as a non-caloric sugar substitute in many kinds of foods, medicine, beverage, cosmetics, wine making, household chemical industry and other food industries [10]. It possesses anti-hyperglycaemic, anti-hypertensive, anti-oxidant, anti-tumor, anti-diarrheal, diuretic, gastro and renal-protective and immunomodulatory properties [11]. The anti-hyperglycemic effect of $S$. rebaudiana was investigated in both rats and humans by $[12,13]$. They mentioned that stevioside demonstrates a positive effect on hyperglycemia through decreasing the absorption of glucose in duodenum, glycogenolysis and gluconeogenesis.

As the synthetic drugs used for the treatment of diabetes result in many complications. Hence the use of natural source (Stevia rebaudiana Bertoni) for the treatment of diabetes is safe and non-carcinogenic [8,9]. Hence, the present experiment was undertaken to study the antidiabetic effect of $S$. rebaudiana in albino rats.

\section{Methods}

\section{Plant material}

Stevia (Stevia rebaudiana Bertoni) leaves were collected from Ayub Agricultural Research Institute (AARI), Faisalabad (Reference no. 606/8). Stevia leaves were washed to remove the dirt, dust and foreign material adhered to the surface. After washing, leaves of stevia were air-dried under shade at room temperature and finely powdered with the help of grinder (MJ-176-NR-3899) [14].

\section{Stevia aqueous extract preparation}

Stevioside was extracted from the dried ground leaves of stevia plant by using water extraction. The dried ground leaves of stevia were mixed with hot water $\left(65^{\circ} \mathrm{C}\right)$ at the ratio of 1:45 $(w / v)$ [15]. The mixture was shaken properly and kept at room temperature for $24 \mathrm{~h}$. It was stirred 2-3 times a day. After $24 \mathrm{~h}$, mixture was filtered through What man filter paper and the filtrate was evaporated using rotary vacuum evaporator (EYELA N-1110S 115V) at $40-45{ }^{\circ} \mathrm{C}[14]$.

\section{Experimental animals}

Sixty adult male albino rats of average weight $152.53 \mathrm{~g}$ were purchased from National Institute of Health, Islamabad, Pakistan, after getting permission from Institution of Animal Ethics Committee (IAEC). The rats were kept in stainless steel wire bottom cages under standard conditions (temperature $25 \pm 2{ }^{\circ} \mathrm{C}$ and $60 \pm 5 \%$ relative humidity with $12 \mathrm{~h}$ light-dark cycle) in environmentally controlled animal house of College of Pharmacology, Faculty of Science and Technology, Government College University, Faisalabad Pakistan. The rats were fed on the freshly prepared basal diet containing $65 \%$ starch, $10 \%$ casein, $10 \%$ corn oil, $4 \%$ salt mixture, $1 \%$ vitamins mixture and $10 \%$ cellulose [16] and distilled water for two week that meets their requirements for growing ad libitum.

\section{Induction of diabetes}

The diabetes was induced in the rats by a single intraperitonial injection of STZ (40 $\mathrm{mg} / \mathrm{kg}$ of body weight) freshly prepared in citrate buffer $(0.1 \mathrm{M}, \mathrm{pH} 4.5)$, into the femoral vein of rats after an overnight fasting [17]. STZ-injected animals were given $20 \%$ glucose solution for $24 \mathrm{~h}$ to prevent initial drug-induced hypoglycemic mortality [5]. The normal control rats received only distilled water and standard diet.

Development of diabetes mellitus in the rats was confirmed by testing fasting blood glucose (FBG), after $72 \mathrm{~h}$ of STZ injection. The rats with FBG higher than $200 \mathrm{mg} / \mathrm{dL}$ were considered diabetic and were selected for the study [18].

\section{Animal groups and experimental design}

Sixty male albino rats were divided into six groups of ten animals each. 1st and 2nd groups included normal (non-diabetic) and diabetic control rats respectively that received only distilled water that was free from impurities like dissolved salts and colloidal particles that can affect the results of the present research and standard diet throughout the whole trial. Diabetic rats consumed Stevia rebaudiana Bertoni aqueous extract dissolved at the levels of 200,300, 400 and $500 \mathrm{ppm} / \mathrm{kg}$ b.w of albino rats in distilled water and administered orally as a daily dose for 8 weeks were included in 3rd, 4th, 5th and 6th groups respectively as shown in Table 1 .

\section{Feed and water intake}

Net feed intake of individual rat was calculated on daily basis by excluding left-over and collected spilled diet during the entire period to determine the effect of individual experimental diet. Water was provided with the help of graduated drinking bottles and its consumption was also measured on daily basis.

\section{Gain in body weight}

Gain in body weight of individual rat in each group was estimated on weekly basis throughout the experimental period to find out the effect of individual diet on body weight using electronic weighing balance (KERN 440-35 N).

\section{Collection of serum of rats}

For the serum, overnight fasted albino rats were killed using $0.4 \mathrm{~mL}$ of urethane anesthesia (25\%) /100 g of body weight. Then blood was collected by cardiac puncture. After that serum was separated by centrifugation in the centrifuge machine (LABCENT 5000) at $3000 \mathrm{rpm}$ for 
Table 1 Addition of aqueous Stevia extract in the distilled water of rats at different substitution levels

\begin{tabular}{|c|c|c|c|c|c|}
\hline \multirow{2}{*}{$\begin{array}{l}\text { Non-diabetic rats } \\
N_{0}\end{array}$} & \multicolumn{5}{|l|}{ Diabetic rats } \\
\hline & $\mathrm{D}_{0}$ & $D_{1}$ & $D_{2}$ & $\mathrm{D}_{3}$ & $D_{4}$ \\
\hline $\begin{array}{l}\text { Control (Basal } \\
\text { diet+ distilled } \\
\text { water) }\end{array}$ & $\begin{array}{l}\text { Control (Basal } \\
\text { diet+ distilled } \\
\text { water) }\end{array}$ & $\begin{array}{l}\text { Basal diet + } \\
200 \text { ppm SAE }\end{array}$ & $\begin{array}{l}\text { Basal diet+ } \\
300 \text { ppm SAE }\end{array}$ & $\begin{array}{l}\text { Basal diet+ } \\
400 \text { ppm SAE }\end{array}$ & $\begin{array}{l}\text { Basal diet+ } \\
500 \text { ppm SAE }\end{array}$ \\
\hline
\end{tabular}

$\mathrm{N}_{0}=$ Basal diet and distilled water

$\mathrm{D}_{0}=$ Basal diet and distilled water

$D_{1}=$ Basal diet and distilled water with 200 ppm Stevia leaf Aqueous extract

$\mathrm{D}_{2}=$ Basal diet and distilled water with 300 ppm Stevia leaf Aqueous extract

$\mathrm{D}_{3}=$ Basal diet and distilled water with $400 \mathrm{ppm}$ Stevia leaf Aqueous extract

$\mathrm{D}_{4}=$ Basal diet and distilled water with 500 ppm Stevia leaf Aqueous extract

$15 \mathrm{~min}$ after allowing the blood to stand for at least $30 \mathrm{~min}$ at room temperature as per standard protocols [19].

\section{Analysis of serum biochemical profile of rats}

Following analysis were made from the collected serum samples.

\section{Random blood glucose and fasting blood glucose levels} Fasting as well as random levels of glucose were estimated within 3 hours of sample collection by "GOD PAP Enzymatic Colorimetric Test Method" [20] on Humalyzer, 3000 ("Semi-automatic chemistry analyzer by Human, Germany, Model no. 16700") by the use of standard kits. Effect of stevia aqueous extract on fasting blood glucose level as well as random blood glucose levels were observed at 1st, 2nd 3rd, 4th, 5th, 6th, 7th and 8th week of drug treatment in order to observe the variation in fasting and random blood glucose levels. For it blood was be taken by making a small cut at terminal tail vein of rats.

\section{Glycosylated hemoglobin (HbA1c) level}

HbA1c in the blood was estimated by the method Nayak and Pattabiraman [21]. First lysed $5.5 \mathrm{~mL}$ of water with saline washed erythrocytes $(0.5 \mathrm{~mL})$, mixed and incubated for $15 \mathrm{~min}$ at $37^{\circ} \mathrm{C}$. The supernatant was discarded after the centrifugation of contents, then for the further process for estimation of $\mathrm{HbA1c}, 0.5 \mathrm{~mL}$ of saline was added and mixed. The contents were heated for $4 \mathrm{~h}$ at $100{ }^{\circ} \mathrm{C}$ after the addition of $0.02 \mathrm{~mL}$ of aliquot and 4 $\mathrm{mL}$ of oxalate hydrochloric solution. The solution was cooled and precipitated with $2 \mathrm{~mL}$ of $40 \%$ TCA. $0.5 \mathrm{~mL}$ of supernatant, $0.05 \mathrm{~mL}$ of $80 \%$ phenol and $3.0 \mathrm{~mL}$ of concentrated $\mathrm{H}_{2} \mathrm{SO}_{4}$ were added, after the centrifugation of the mixture. After $30 \mathrm{~min}$, the color was developed that was read at $480 \mathrm{~nm}$.

\section{Insulin level}

The plasma insulin was assayed by Enzyme Linked Immunosorbent Assay (ELISA) method using Boehringer-Mannheim kit [22]. $0.1 \mathrm{~mL}$ of plasma was injected into the plastic tubes coated with monoclonal anti-insulin antibodies. To form anti-insulin antibody-POD conjugate, phosphate buffer and anti-insulin POD conjugate was added. Indicators reaction was formed by the addition of substrate chromogen solution. Then in the similar manner, a set of standards were also treated. The absorbance was read after the development of color at $420 \mathrm{~nm}$.

\section{Liver glycogen}

Liver glycogen level was measured according to the standard protocol [23]. Liver of both diabetic and non-diabetic rats was removed immediately at the end of the experiment and washed using ice-cold saline solution. Then hepatic tissues were minced and homogenized in hot ethanol (80\%) at a tissue concentration of $100 \mathrm{mg} / \mathrm{mL}$ and centrifuged in the centrifuge machine (LABCENT 5000) at $9500 \mathrm{rpm}$ for $20 \mathrm{~min} .5 \mathrm{~mL}$ water and $6 \mathrm{~mL}$ of $52 \%$ perchloric acid were added. From it the residue was collected, dried and extracted. The collected material was centrifuged at $9500 \mathrm{rpm}$ for 15 min for the recovery of supernatant. In the graduated test tube, $0.2 \mathrm{~mL}$ of supernatant, $1 \mathrm{~mL}$ distilled water and anthrone reagent $(4 \mathrm{~mL})$ was added, heated, cooled at room temperature and at $630 \mathrm{~nm}$ the intensity of the green to dark green color of the solution was recorded. From a standard curve prepared with standard glucose solution, glycogen content of the sample was determined.

\section{Statistical analysis}

Results are expressed as mean \pm standard deviation (SD). Analysis of variance (ANOVA) and least significance difference (LSD) were carried out on the result data at $95 \%$ confidence level using SPSS statistical software package, version 17 (SPSS Inc., Chicago).

\section{Results}

Means values for feed and water intakes in different groups of rats (per rat/day) have been shown graphically in Figs. 1 and 2. The results demonstrated that administration of stevia sweetener reduced the feed and water intakes in diabetic rats than $\mathrm{N}_{0}$ and $\mathrm{D}_{0}$. The highest feed and water intakes $14.57 \mathrm{~g} / \mathrm{rat} /$ day, $29.82 \mathrm{~mL} /$ day and $13.14 \mathrm{~g} / \mathrm{rat} /$ day, $28.95 \mathrm{~mL} /$ day respectively were observed in $\mathrm{N}_{0}$ (non-diabetic control) and $\mathrm{D}_{0}$ (diabetic control). While stevia sweetener at 


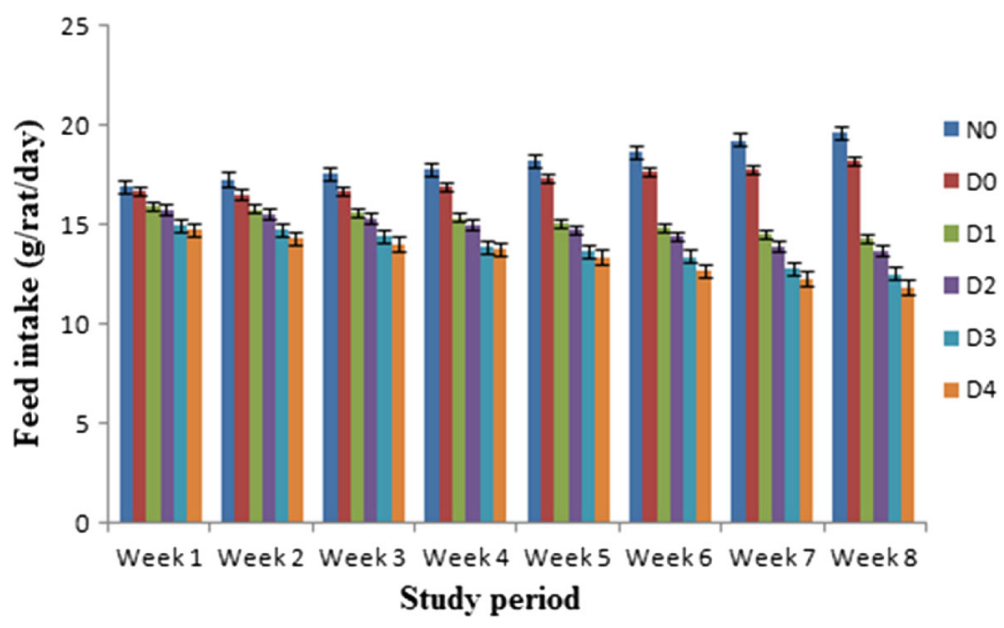

Fig. 1 Feed intake $(\mathrm{g})$ in normal and diabetic rats during 8 weeks (rat/week). Results are expressed as amount of feed intake levels of diabetic and non-diabetic rats (mean \pm standard deviation $(S D) . n=10$ ). The feed intake of diabetic rats $\left(D_{1}, D_{2}, D_{3}\right.$ and $\left.D_{4}\right)$ received stevia aqueous extract in different concentrations $\left(200,300,400\right.$ and 500 ppm) respectively significantly $(P<0.05)$ decreased from non-diabetic $\left(N_{0}\right)$ and diabetic $\left(D_{0}\right)$ control groups

dose of $500 \mathrm{ppm} / \mathrm{kg}$ b.w showed the lowest amounts of feed and water intake $(13.38 \pm 0.98 \mathrm{~g} / \mathrm{rat} /$ day $)$ and $(24.38 \pm 0.58 \mathrm{~mL} /$ day $)$ followed by $200 \mathrm{ppm} / \mathrm{kg}$ b.w $(15.20 \pm 1.00 \mathrm{~g} /$ day $),(26.26 \pm 0.53 \mathrm{~mL} /$ day $), 300 \mathrm{ppm} / \mathrm{kg}$ b.w $(14.81 \pm 0.97 \mathrm{~g} / \mathrm{rat} /$ day $),(25.68 \pm 0.60 \mathrm{~mL} /$ day $)$ and $400 \mathrm{ppm} / \mathrm{kg}$ b. wt $(13.82 \pm 0.99 \mathrm{~g} / \mathrm{rat} /$ day $), \quad(25.10 \pm$ $0.64 \mathrm{~mL} /$ day) of stevia extracts respectively (Figs. $1 \& 2$ ).

Effect of administration of stevioside on the body weight of rats has been shown in Table 2. It is apparent from the results that the highest body weights $(154.60 \pm 4.02-185.90 \pm 5.87 \mathrm{~g} / \mathrm{rat})$ and $(153.22 \pm 4.22-$ $179.32 \pm 4.55 \mathrm{~g} / \mathrm{rat}$ ) were observed in $\mathrm{N}_{0}$ (normal control) and $\mathrm{D}_{0}$ (diabetic control). While the lowest body weight was recorded in $\mathrm{D}_{4}$ (diabetic rats received $500 \mathrm{ppm} / \mathrm{kg}$ b.w aqueous stevia extract) (148.60 $\pm 7.02-120.81 \pm$ $7.80 \mathrm{~g} / \mathrm{rat})$ as followed by $\mathrm{D}_{1}(152.12 \pm 5.01-132.78 \pm$ $4.32 \mathrm{~g} / \mathrm{rat}), \mathrm{D}_{2}(150.30 \pm 6.33-128.70 \pm 4.54 \mathrm{~g} / \mathrm{rat})$ and $\mathrm{D}_{3}$ $(149.82 \pm 6.88-124.32 \pm 6.10 \mathrm{~g} / \mathrm{rat})$ during study period from 1 st week to 8 weeks.

Regarding the body weight gain \%, highest percentage (23.27\%) and (19.48\%) was observed in $\mathrm{N}_{0}$ and $\mathrm{D}_{0}$. When diabetic rats were given stevia sweetener then their body weight gain \% decreased by $-13.84,-15.89,-18.75$ and $20.55 \%$ respectively after 8 weeks (Table 2 ).

Table 3 represents the random blood glucose levels of normal and diabetic rats, affected by different levels of stevia aqueous extracts. From the results, it was observed that random blood glucose (RBG) levels of $\mathrm{N}_{0}$

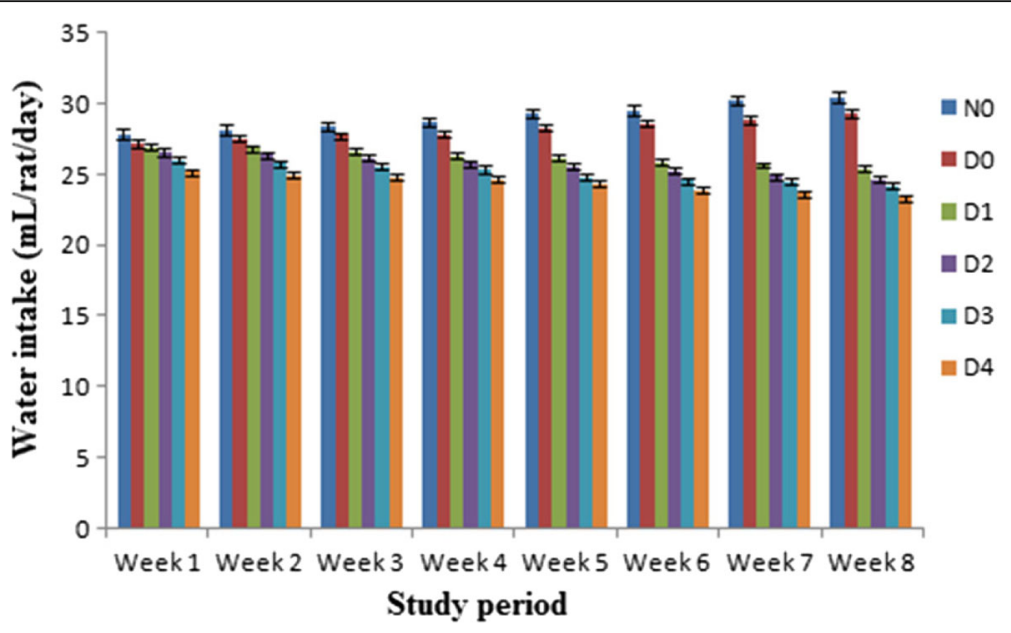

Fig. 2 Water intake $(\mathrm{mL})$ in normal and diabetic rats during 8 weeks (rat/week). Results are expressed as amount of water intake levels of diabetic and non-diabetic rats (mean \pm standard deviation $(S D) . n=10)$. The water intake of diabetic rats $\left(D_{1}, D_{2}, D_{3}\right.$ and $\left.D_{4}\right)$ received stevia aqueous extract in different concentrations $\left(200,300,400\right.$ and 500 ppm) respectively significantly $(P<0.05)$ decreased from non-diabetic $\left(N_{0}\right)$ and diabetic $\left(D_{0}\right)$ control groups 


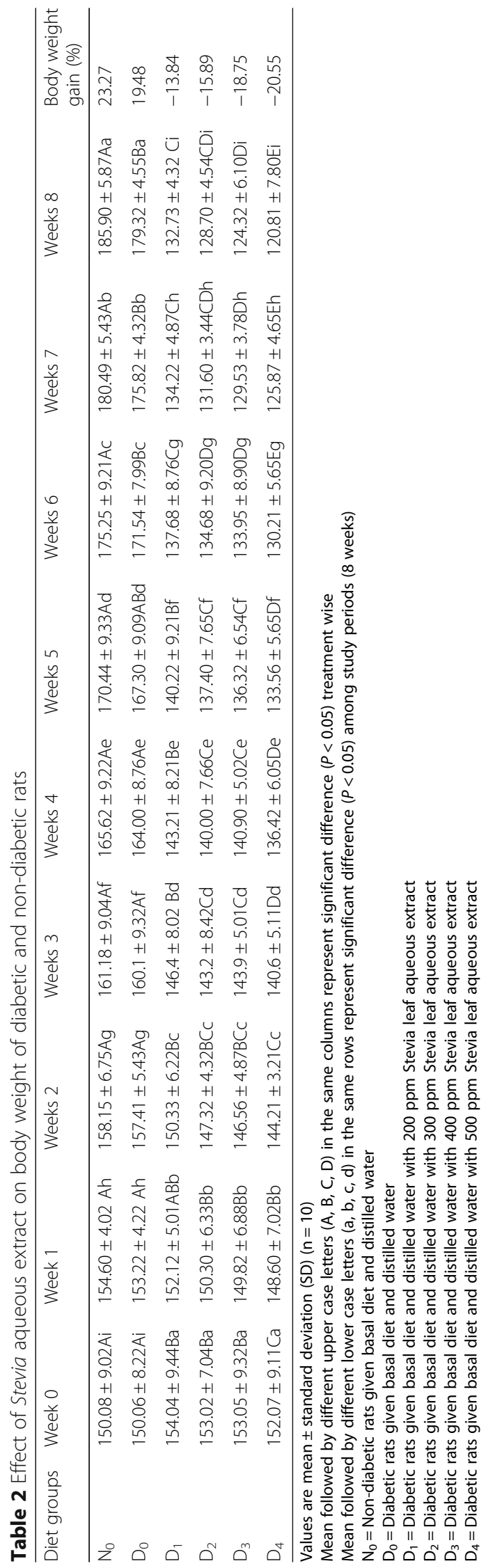




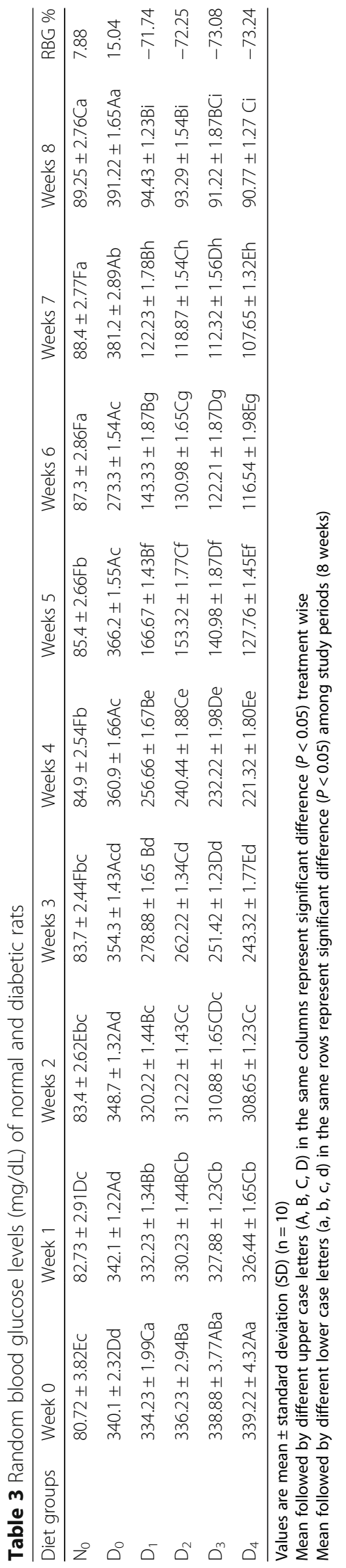


and $\mathrm{D}_{0}$ increased from $(82.73 \pm 2.91$ to $89.25 \pm 2.76 \mathrm{mg} / \mathrm{dL})$ and $(342.1 \pm 1.22$ to $391.22 \pm 1.65 \mathrm{mg} / \mathrm{dL})$ respectively at the beginning of the study to end of trail respectively. However, the RBG levels of $D_{1}, D_{2}, D_{3}$ and $D_{4}$ decreased from $332.23 \pm 1.34, \quad 330.23 \pm 1.44, \quad 327.88 \pm 1.23$ and $326.44 \pm$ $1.65 \mathrm{mg} / \mathrm{dL}$ at 1 st week to $94.43 \pm 1.23,93.29 \pm 1.54,91.22$ \pm 1.87 and $90.77 \pm 1.27 \mathrm{mg} / \mathrm{dL}$ respectively at 8 th week (Table 3). Stevia extract decreased the random blood glucose \% levels of groups $\mathrm{D}_{1}, \mathrm{D}_{2}, \mathrm{D}_{3}$ and $\mathrm{D}_{4}$ by -71.74 , $72.25,-73.08$ and $-73.24 \%$ respectively after 8 weeks (Table 3).

As presented in Table 4 , there was significant $(P<0.05)$ increase in the fasting blood glucose level of the diabetic control group rats, relative to the normal control group. However, this was significantly $(\mathrm{P}<0.05)$ restored toward normal in the diabetic rats given stevia aqueous extract, as indicated by the decrease in their fasting blood glucose levels from the 1st week to the 8th week. According to results highest level of fasting blood glucose (306.4 \pm $2.65 \mathrm{mg} / \mathrm{dL}$ ) was recorded in $\mathrm{D}_{0}$ (diabetic control group rats). While fasting blood glucose levels of diabetic rats received stevia aqueous extract significantly decreased from $90.70 \pm 2.98\left(\mathrm{D}_{1}\right)$ to $88.22 \pm 2.97\left(\mathrm{D}_{4}\right) \mathrm{mg} / \mathrm{dL}$. The fasting blood glucose \% levels of groups $D_{1}, D_{2}, D_{3}$ and $D_{4}$ decreased by $-64.87,-65.28,-65.96$ and $-66.09 \%$ respectively after 8 weeks (Table 4 ).

The glycosylated hemoglobin (HbA1c) level of the rats is shown in Fig. 3. According to results HbA1c level $(9.27 \pm 1.09 \%)$ of $\mathrm{D}_{0}$ significantly $(P<0.05)$ increased than $\mathrm{N}_{0}(5.92 \pm 1.02 \%)$. But as compared to the $\mathrm{D}_{0}$, diabetic groups $D_{1}, D_{2}, D_{3}$ and $D_{4}$ received stevia aqueous extract had significantly $(P<0.05)$ lower HbA1c levels $(6.22 \pm 1.11 \%, \quad 6.06 \pm 1.08 \%, \quad 5.77 \pm 1.06 \%$ and $5.32 \pm$ $1.00 \%)$ respectively; indicating that the stevia extract decrease the glycosylation of hemoglobin.

The insulin levels of diabetic and normal rats are shown in Fig. 4. According to results the insulin levels of diabetic $\mathrm{D}_{0}(15.89 \pm 1.22 \mu \mathrm{IU} / \mathrm{mL})$ control group decreased as compared to $\mathrm{N}_{0}(18.02 \pm 1.44$ $\mu \mathrm{IU} / \mathrm{mL})$. The results of this study concluded that diabetic rats given stevioside mixed in distilled water increased the levels of serum insulin. The results further demonstrated that given stevia aqueous extracts at different dose levels improved significantly $(P<0.05)$ from $16.04 \pm 1.24$ to $17.82 \pm 1.33 \mu \mathrm{IU} / \mathrm{mL}$ $\left(D_{1}\right.$ to $\left.D_{4}\right)$ (Fig. 4$)$.

The liver glycogen level of the rats is shown in Fig. 5. In this study, glycogen level of $D_{0}(17.07 \pm 1.35 \mathrm{mg} / \mathrm{g})$ decreased significantly $(\mathrm{P}<0.05)$ compared to the $\mathrm{N}_{0}$ $(45.22 \pm 2.22 \mathrm{mg} / \mathrm{g})$ (Fig. 5). However, the diabetic rats received stevia aqueous extracts $(200,300,400$ and $500 \mathrm{ppm} / \mathrm{kg})$ significantly $(P<0.05)$ increased the liver glycogen levels $(35.27 \pm 2.12,37.43 \pm 2.14,42.66 \pm 2.20$ and $45.02 \pm 2.24 \mathrm{mg} / \mathrm{g}$ ) (Fig. 5).

\section{Discussion}

In this study, we evaluated the anti-diabetic activity of aqueous extract of stevia in diabetic albino rats as previous researches confirmed its pharmacological importance due to presence of glycosides like stevioside in it. Administration of aqueous stevia extract orally at different concentrations $(200,300,400$ and $500 \mathrm{mg} / \mathrm{kg}$ ) for 8 weeks, significantly decline the feed and water intakes of diabetic albino rats. Stevia a low-caloric sweetener may reduce the feed and water intake and not promote weight gain because they do not stimulate the appetite [24]. Similarly, stevia sweetener at doses of 25, 250, 500 and $1000 \mathrm{mg} / \mathrm{kg} \mathrm{b}$. w may also reduce the feed intake in adult female wistar strain rats [25].

The results indicated that aqueous extract from leaves of Stevia rebaudiana, produced a significant $(P<0.05)$ dose-dependent reduction in body weight (Table 2) and body weight gain percentage of the rats treated with Stevia extract (Table 3) as compared to $\mathrm{N}_{0}$. The highest gain in body weight was noticed in $\mathrm{N}_{0}$ while lowest was recorded in $\mathrm{D}_{4}$. Stevioside in the diet lowered the blood glucose level. The body weight of rats might reduce due to lower metabolisation of diet glucose or decrease amount of rat's food consumption [26]. This reduction in weights of rats receiving stevia extract may be due to high amount of stevioside that reduced the food intake of rats [27]. This finding is collaborated with the previous researches which proved a positive association between the decrease of body weight gain percent and the decline in feed intake and dose of stevioside given to the rats [28-30].

This study depicted that different concentrations of stevia extract had a good efficacy in controlling diabetes with an excellent control of random and fasting blood glucose level in diabetic rats at study period of 8 weeks. Previous study showed that stevioside was able to regulate blood glucose levels by enhancing not only insulin secretion and sensitivity but also insulin utilization in insulin deficient rats which was due to decreased PEPCK gene expression in rat liver [31]. According to another study, stevia extract may contain some biomolecules that may sensitize the insulin receptor to insulin or stimulates the $\beta$-cells of islets of langerhans to release insulin which may finally lead to improvement of carbohydrate metabolizing enzymes towards the reestablishment of normal blood glucose level [32]. Stevia rebaudiana leaves extract decreased the random and fasting blood glucose levels of rats by revitalizing the $\beta$-cells of pancreas thus reactivated the glycogen synthase system by improving insulin secretion and liver glycogen level [25, 27, 33, 34]. These results are in agreement with Awney et al. [27]; Abo Elnaga et al. [25]; Assaei et al. [30] and Akbarzadeh et al. [34] who also observed that stevia aqueous extract lowered the random and fasting blood 


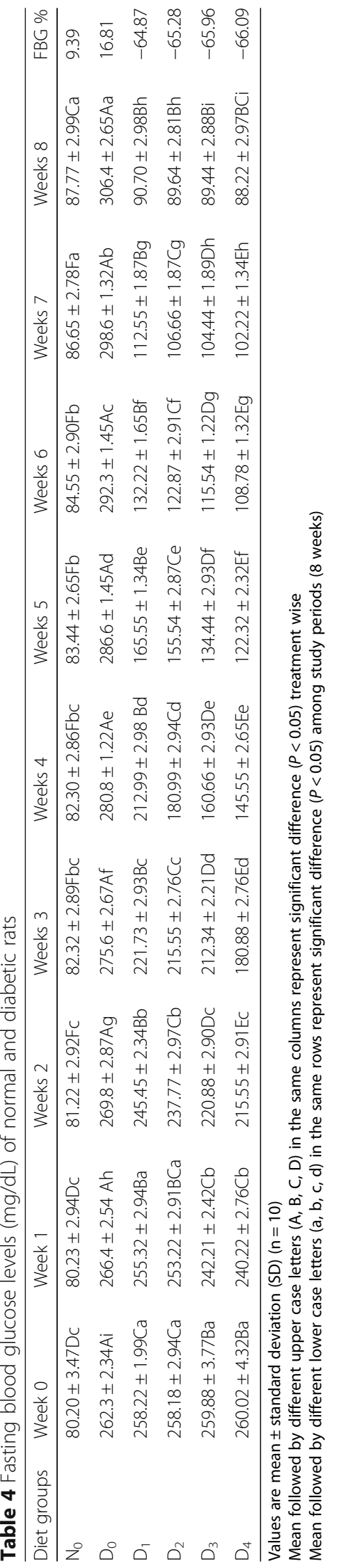




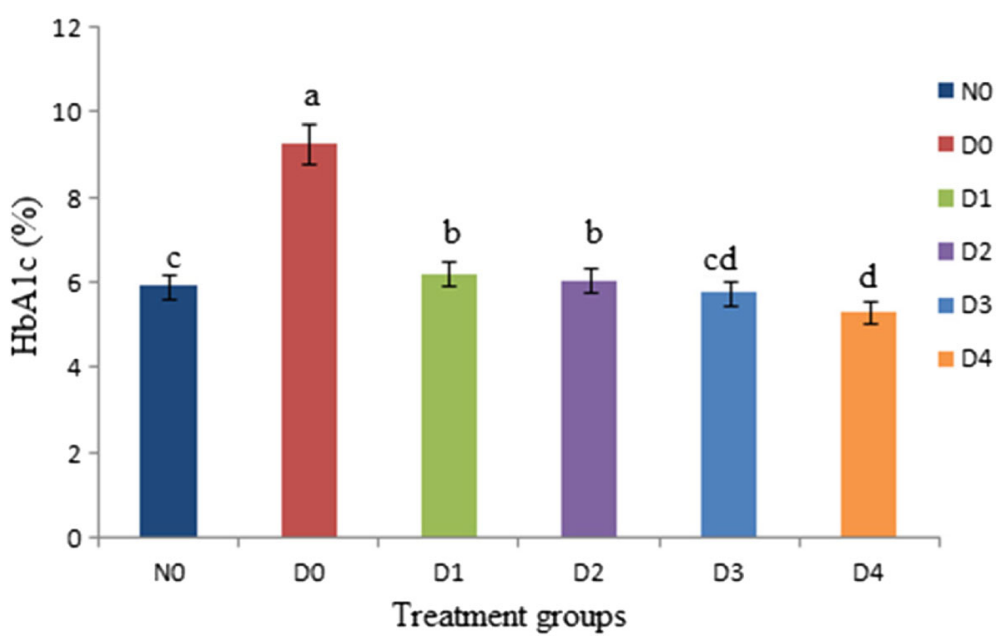

Fig. 3 Effect of Stevia aqueous extract on the glycosylated hemoglobin (HbA1c) level of the rats. Results are expressed as percentage of HbA1c levels of diabetic and non-diabetic rats (mean \pm standard deviation $(S D) . n=10) . a, b, c$, d represent significant difference $(P<0.05)$ in $H b A 1 c$ levels treatment wise. HbA1c levels of diabetic rats $\left(D_{1}, D_{2}, D_{3}\right.$ and $\left.D_{4}\right)$ received stevia aqueous extract in different concentrations (200, 300, 400 and $500 \mathrm{ppm})$ respectively significantly $(P<0.05)$ decreased as compared diabetic $\left(D_{0}\right)$ control groups and near to $N_{0}$

glucose levels in diabetic rats due to more insulin secretion and increased glycogen level.

The diabetic rats treated with stevia aqueous extract exhibited HbA1c values near normal levels $(\geq 6.5 \%$ $(48 \mathrm{mmol} / \mathrm{mol})$ as a result of improved glycemic control due to initiation of glycogen production framework of the extract. The decrease of HbAlc showed that the ability of extract to control the diabetes [33].

These results are in accordance with Prasad et al. [35] and Rao et al. [36] who demonstrated the anti-diabetic effects of ethanolic extract of the roots of Chonemorpha fragrans and combination of herbal product (Curcuma longa and Eugenia jambolana) in streptozotocin- induced diabetic rats and concluded that both have a good efficacy in controlling diabetes.

The serum insulin level in the diabetic control group decreased due to STZ that resulted in diabetes by the rapid depletion of $\beta$-cells, which reduced the insulin release. An insufficient release of insulin causes hyperglycemia, which results in oxidative damage by the generation of reactive oxygen species and the development of diabetic complications [37]. When stevia aqueous extracts at different dose levels were given to the diabetic albino rats then their insulin levels improved significantly (Fig. 4) due to the presence of natural components (stevioside) in stevia leaves that are related to

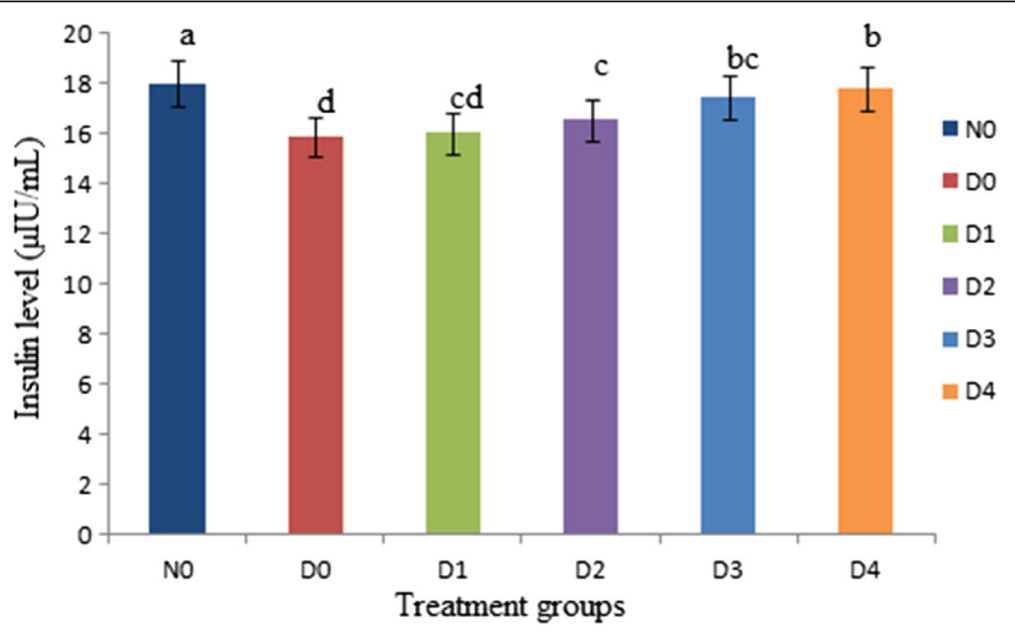

Fig. 4 Effect of Stevia aqueous extract on insulin levels of different groups of rats. Results are expressed as concentration of insulin levels of diabetic and non-diabetic rats (mean \pm standard deviation (SD). $n=10)$. a, b, c, d represent significant difference $(P<0.05)$ in insulin levels treatment wise. The insulin levels of diabetic rats $\left(D_{1}, D_{2}, D_{3}\right.$ and $\left.D_{4}\right)$ received stevia aqueous extract in different concentrations $(200,300,400$ and $500 \mathrm{ppm}$ ) respectively significantly $(P<0.05)$ increased as compared diabetic $\left(D_{0}\right)$ control groups and near to $N_{0}$ 


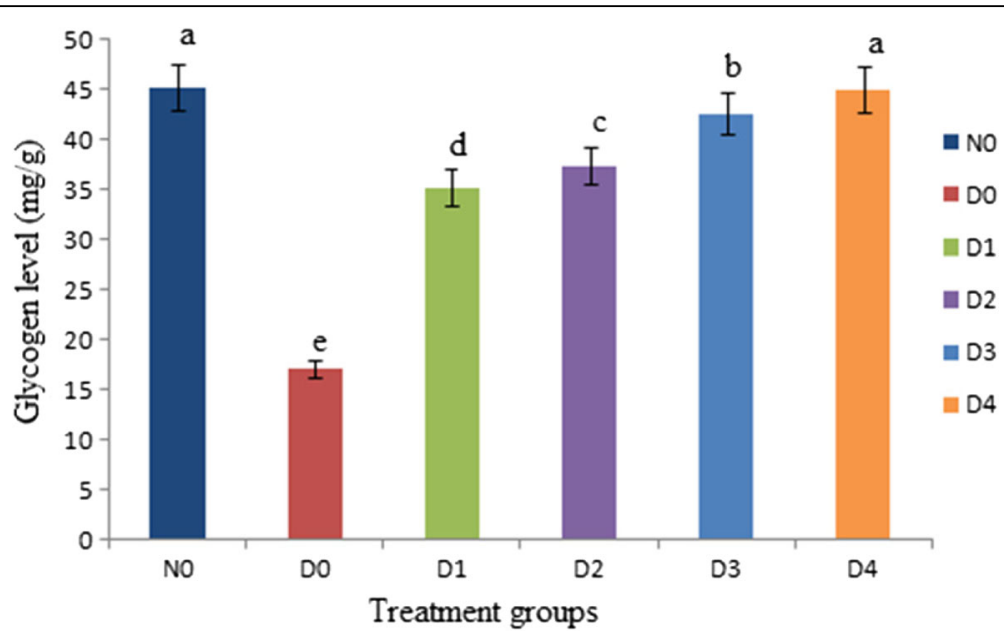

Fig. 5 Effect of Stevia aqueous extract on the glycogen level of the rats. Results are expressed as concentration of glycogen levels of diabetic and non-diabetic rats (mean \pm standard deviation (SD). $n=10)$. a, b, c, d represent significant difference $(P<0.05)$ in insulin levels treatment wise. The glycogen levels of diabetic rats $\left(D_{1}, D_{2}, D_{3}\right.$ and $\left.D_{4}\right)$ received stevia aqueous extract in different concentrations $(200,300,400$ and 500 ppm) respectively significantly $(P<0.05)$ increased as compared diabetic $\left(D_{0}\right)$ control groups and near to $N_{0}$

inhibition of hepatic expression of phosphoenolpyruvate carboxykinase and gluconeogenesis coupled with stimulation of hepatic glycogen synthesis that resulted in increase of insulin secretion and insulin sensitivity [38]. Evidence from other studies revealed that stevia aqueous extract elevate the insulin level due to stevioside that acts on pancreatic tissue, exerts beneficial anti-hyperglycemic effects through the PPAR $\gamma$-dependent mechanism $[34,30]$.

The results are in collaborations with the studies conducted by Shivanna et al. [39]; Saleh et al. [40] and Abou khalil et al. [41] who concluded that aqueous extracts of Stevia rebaudiana leaves and Desert date (Balanites aegyptiaca) and Parsley (Petroselinum sativum) stevioside normalize the pancreatic cell function by restoring the insulin immune reactivity in STZ-induced diabetic rats.

The reduction in insulin release and liver glycogen level of diabetic control group rats are due to STZ (a known diabetogen) used for induction of diabetes in rats that brings about the destruction of $\beta$ - cells of the islets of Langerhans [42]. However, the diabetic rats received stevia aqueous extracts $(200,300,400$ and $500 \mathrm{ppm} / \mathrm{kg})$ were able to significantly $(P<0.05)$ improve the liver glycogen levels (Fig. 5). Stevioside (sweetener) present in stevia extract acts directly on pancreatic beta cells and resulted in increase of insulin secretion [12]. Increased level of Insulin enhances intracellular glycogen deposition by stimulating activities of glycogen synthase and inhibiting glycogen phosphorylase [38].

Similar results were observed by previous researchers who found that Plectranthus esculenthus extracts and Mangifera indica kernel flour-supplemented diet restored the liver glycogen levels in STZ induced diabetic rats $[42,43]$.

\section{Conclusions}

The present study suggests that aqueous extract from stevia leaves may decrease the random blood glucose level and fasting blood glucose and glycosylated (HbA1c) hemoglobin while insulin and liver glycogen levels significantly increased of the diabetic rats, compared with the diabetic and non-diabetic control rats after 8 weeks study period. It is concluded that aqueous extact of stevia with concentration $500 \mathrm{ppm} / \mathrm{kg}$ body weight of rats showed best results of all the parameters determined. It is understood from the results that stevia extract has anti-diabetic effects in albino rats, and therefore could be used as natural anti-diabetic drug for the treatment of diabetes and its associated complications.

\section{Abbreviations \\ BWG \%: Body weight gain percentage; FBG: Fasting blood glucose; HbA1c: Glycosylated hemoglobin; PEPCK: Phosphoenolpyruvate carboxykinase; RBG: Random blood glucose; STZ: Streptozotocin}

\section{Acknowledgements}

The authors are thankful to the Institute of Home and Food Sciences, Government College University Faisalabad Pakistan for providing research facilities to prepare this valuable document.

\section{Availability of data and materials}

Available on request.

\section{Authors' contributions}

UA conceptualized and performed the study; RSA provided the technical assistance, guided in the data collection and also helped to analyze the data and drafting the manuscript. Both authors read and approved the final manuscript.

\section{Ethics approval}

Before doing the research, ethical approval was obtained from Institutional Review Board Faculty of Science \& Technology, Government College University, Faisalabad, Pakistan (IRB no. 0093106, 2/10/2017). The procedure followed the instructions of Good Laboratory Practice (GLP). 


\section{Competing interests}

The authors declare that they have no competing interests.

\section{Publisher's Note}

Springer Nature remains neutral with regard to jurisdictional claims in published maps and institutional affiliations.

\section{Received: 22 February 2018 Accepted: 30 May 2018}

\section{Published online: 11 June 2018}

\section{References}

1. American Diabetes Association. Diagnosis and classification of diabetes mellitus. Diabetes Care. 2014;37(Suppl 1):S81-90.

2. Mathers CD, Loncar D. Projections of global mortality and burden of disease from 2002 to 2030. PLoS Med. 2006;3(11):e442.

3. Li G, Zhang P, Wang J, Gregg EW, Yang W, Gong Q. The long- term effect of life style interventions to prevent diabetes in the China Da Qing diabetes prevention study: a 20-year follow-up study. Lancet. 2008;371:1783-9.

4. Dhasarathan P, Theriappan P. Evaluation of anti-diabetic activity of Strychonous potatorum in alloxan induced diabetic rats. J Med Sci. 2011;2(2): 670-4.

5. Ramesh B, Pugalendi KV. Anti-hyperglycemic effect of Umbelliferone in Streptozotocin diabetic rats. J Med. Plants. 2006;9(4):562-6.

6. Loew D, Kaszkin M. Approaching the problem of bioequivalence of herbal medicinal products. Phytother Res. 2002;16:705-11.

7. Anbazhagan M, Kalpana M, Rajendran R, Natarajan V, Dhanavel D. In vitroproduction of Stevia rebaudiana Bertoni. EJFA. 2010;22(3):216-22.

8. Brahmachari G, Mandal LC, Roy R, Mondal S, Brahmachari AK. Stevioside and related compounds-molecules of pharmaceutical promise: a critical overview. Arch Pharm Chem Life Sci. 2011;1:5-19.

9. Lemus-Mondaca R, Vega-Galvez A, Zura-Bravo L, Ah-Hen K. Stevia rebaudiana Bertoni, source of a high-potency natural sweetener: a comprehensive review on the biochemical, nutritional and functional aspects. J Food Chem. 2012;132:1121-32.

10. Stoyanova S, Genus J, Heideg E, Den Ende WV. The food additives insulin and stevioside counteract oxidative stress. Int J Food Sci Nutr. 2011;62:207-14.

11. Ferrazzano GF, Cantile T, Alcidi B, Coda M, Ingenito A, Zarrelli A, Fabio GD, Pollio A. Is Stevia rebaudiana Bertoni a non cariogenic sweetener? A review. Molecules. 2016;21:1-38. https://doi.org/10.3390/molecules21010038.

12. Jeppesen PB, Gregersen S, Rolfsen SE, Jepsen M, Colombo M, Agger A, Xiao J, Kruhoffer M, Orntoff T, Hermansen K. Antihyperglycemic and blood pressure-reducing effects of stevioside in the diabetic Goto-Kakizaki rat. Metabolism. 2003;52:372-8.

13. Thomas JE, Stevia GMJ. It's not just about calories. The Open Obesity Journal. 2010;2:101-9.

14. Kujur RS, Singh V, Ram M, Yadava HN, Singh KK, Kumari S, Roy BK. Antidiabetic activity and phytochemical screening of crude extract of Stevia rebaudiana in alloxan-induced diabetic rats. Pharm Res. 2010:2(4):258-63.

15. Abou-Arab AE, Abou-Arab AA, Abu-Salem MF. Physico-chemical assessment of natural sweeteners steviosides produced from Stevia rebaudiana Bertoni plant. Afr J Food Sci. 2010;4:269-81.

16. AOAC. Official Methods of Analysis of the Association of Official Analytical Chemists International. 17th ed. Arlington, VA, USA: Association of Official Analytical Chemists International; 2000.

17. Parveen $\mathrm{K}$, Khan $\mathrm{R}$, Siddiqui WA. Antidiabetic effects afforded by Terminalia arjunain high fat- fed and streptozotocin-induced type 2 diabetic rats. Int J Diab Metab. 2011;19:23-33.

18. Ashish B, Swapnil G, Baldi A. Hypoglycemic, effect of Polyherbal formulation in Alloxan induced diabetic rats. PhOL. 2011;13:764-73.

19. Uchida K, Satoh T, Ogura Y, Yamaga N, Yamada K. Effect of partial ilea bypass on. cholesterol and bile acid metabolism in rats. Yanago. Acta Medica. 2001;44:69-77.

20. Trinder P. Determination of glucose in blood using glucose oxidase with an alternative.oxygen receptor. Ann Clin Biochem. 1969;6:24-7.

21. Nayak SS, Pattabiraman TN. A new calorimetric method for the estimation of glycosylated haemoglobin. Clin Chim Acta. 1981;109:267-74.

22. Andersen L, Dinesen B, Jorgesen PN, Poulsen F, Roder MF. Enzyme immuno assay for intact human insulin in serum or plasma. Clin Chim Acta. 1993;38: 578-85.

23. Babu V, Gangadevi T, Subramoniam A. Antidiabetic activity of ethanol extract of Cassia kleinii leaf in streptozotocin-induced diabetic rats and isolation of an active fraction and toxicity evaluation of the extract. Indian J Pharmacol. 2003:35(5):290-6.

24. Robarts MW, Wright JT. Sweetness without sugar. Dimeus Dental Hygiene. 2010;8:8-61.

25. Abo Elnaga NIE, Massoud Mona I, Yousef MI, Mohamed Hayam HA. Effect stevia sweetener consumption as non-caloric sweetening on body weight gain and biochemical parameters in over weight female rats. Annals Agri Sci. 2016:61(1):155-63.

26. Chang JC, Wu MC, Liu IM, Cheng JT. Increase of insulin sensitivity by stevioside in fructose-rich chow-fed rats. Horm Metab Res. 2005;37:610-6.

27. Awney $\mathrm{H}$, Massoud M, El-Maghrabi S. Long-term feeding effects of stevioside sweetener on some toxicological parameters of growing male rats. J Appl Toxicol. 2010;31:431-8.

28. Bernal J, Mendiola J, Ibanez E, Cifuentes A. Advanced analysis of nutraceuticals. J Pharm Biomed Anal. 2011;55:758-74.

29. Abd El-Razek AM, Massoud MI. Biological evaluation of aqueous extract of Stevia. rebaudiana leaves. Egypt J Food Sci. 2012;40:47-61.

30. Assaei R, Mokarram P, Dastghaib S, Darbandi S, Darbandi M, Zal F, Akmali M, GHR O. Hypoglycemic effect of aquatic extract of Stevia in pancreas of diabetic rats: PPARy-dependent regulation or antioxidant potential. Avicenna J med Biotech. 2016;8(2):65-74.

31. Geuns JMC, Buyse J, Vankeirsbilck A, Temme EHM. Metabolism of stevioside by healthy subjects. Exp Biol Med. 2007;232:164-73.

32. Hossain MS, Alam MB, Asadujiaman M, Islam MM, Rahman MA, Islam MA, Islam A. Antihyperglycemic and anti hyperlipidemic effects of different fractions of stevia rebaudiana leaves in alloxan-induced diabetic rats. Int J Pharm Sci Res. 2011;2(7):1722-9.

33. Shirwaikar A, Rajendran K, Punitha ISR. Antidiabetic activity of alcoholic stem extract of Coscinium fenestratum in streptozotocin-nicotinamide induced type 2 diabetic rats. J Ethnopharmacol. 2005;97(2):369-74.

34. Akbarzadeh S, Eskandari F, Tangestani H, Bagherinejad ST, Bargahi A, Bazzi P, Daneshi A, Sahrapoor A, O'Connor WJ, Rahbar AR. The effect of Stevia rebaudiana on serum omentin and visfatin level in stz-induced diabetic rats. J diet Suppl. 2015;12(1):1-12.

35. Prasad BS, Srinivasan KK, Harindran J. Chonemorpha Fragrans (moon) Alstonan effective Antihyperglycemic and anti hyperlipidemic agent in Streptozotocin nicotinamide induced diabetic rats. Int J Pharm Sci Res. 2016;7(3):1149-55

36. Rao SS, Najam R. Efficacy of combination herbal product (curcuma longaand Eugenia jambolana) used for diabetes mellitus. Pak J Pharm Sci. 2016;29(1):201-4.

37. Kangralkar V, Shivraj A, Patil D, Bandivadekar RM. Oxidative stress and diabetes: a review. Inter J Pharmaceut Appl. 2010;1:38-45.

38. Yang PS, Lee JJ, Tsao CW, Wu HT, Cheng JT. Stimulatory effect of stevioside on peripheral muopioid receptors in animals. Neurosci Lett. 2009;454(1):72-5.

39. Shivanna N, Naika M, Khanum F, Kaul VK. Antioxidant, anti-diabetic and renal protective properties of Stevia rebaudiana. J Diab Compl. 2013;27:103-13.

40. Saleh OM, Awad NS, Soliman MM, Mansour AA, Nassan MA. Insulin-mimetic activity of stevioside on diabetic rats: biochemical, molecular and histopathological study. Afr J Tradit Complement Altern Med. 2016;13(2): 156-63.

41. Abou Khalil NS, Abou-Elhamd Alaa S, Wasfy Salwa IA, El Mileegy Ibtisam MH, Hamed Mohamed Y, Ageely Hussien M. Antidiabetic and antioxidant impacts of desert date (Balanites aegyptiaca) and parsley (Petroselinum sativum) aqueous extracts: lessons from experimental rats. J Diab Res 2016; Article ID 8408326, 10 pages http://dx.doi.org/10.1155/2016/8408326, 2016.

42. Irondi EA, Oboh G, Akindahunsi AA. Antidiabetic effects of Mangifera indica kernel flour- supplemented diet in streptozotocin-induced type 2 diabetes in rats. J Food Sci Nutri. 2016:4(6):828-39.

43. Jayaprasad B, Sharavanan PS, Sivaraj R. Antidiabetic effect of Chloroxylon swietenia bark extracts on streptozotocin induced diabetic rats. Beni-Suef University J Basic. Appl Sci. 2016;5(1):61-9. 